\title{
Clinical efficacy of duodenoscopy combined with laparoscopy in the treatment of patients with severe acute pancreatitis and pancreatic pseudocyst, and the effects on IL-6 and CRP
}

\author{
LIANHUA ZHENG ${ }^{1}$, SHASHA HUANG ${ }^{2}$, FENGJI LIU $^{3}$ and JUAN YANG ${ }^{3}$ \\ ${ }^{1}$ Medical Record Room; Departments of ${ }^{2}$ Weifang City Disinfection Supply Quality Control Center and ${ }^{3}$ General Surgery, \\ Weifang People's Hospital, Weifang, Shandong 261041, P.R. China
}

Received September 20, 2019; Accepted August 13, 2020

DOI: $10.3892 /$ etm.2020.9487

\begin{abstract}
The study aimed to investigate the clinical efficacy of duodenoscopy combined with laparoscopy in the treatment of patients with severe acute pancreatitis (SAP) and pancreatic pseudocyst (PP), and its effects on serum inflammatory factors. Altogether 94 patients complicated with SAP and PP who were admitted to Weifang People's Hospital (Weifang, China) from September 2015 to December 2018 were included. Based on the different operation methods, 49 patients who underwent traditional laparotomy under laparoscopic surgery were included in group A, and 45 patients who underwent duodenoscopy and laparoscopy under duodenoscope to treat the drainage of nipple and pancreatic pseudocysts were included in group B. The expression levels of related serum indexes and serum stress indexes before and at $48 \mathrm{~h}$ after surgery, the postoperative nausea, vomiting and abdominal pain scores, as well as the clinical efficacy, perioperative related indexes, recovery and complications were compared between the two groups. The prognostic factors in both groups were assessed via Logistic univariate and multivariate analyses. C-reactive protein (CRP), tumor necrosis factor- $\alpha$ (TNF- $\alpha)$, interleukin-6 (IL-6), interleukin- $\beta$ (IL- $\beta$ ), endotoxin and nuclear factor $\kappa \mathrm{B}(\mathrm{NF}-\kappa \mathrm{B})$ were significantly lower in group $\mathrm{B}$ than those in group $\mathrm{A}(\mathrm{P}<0.001)$. Upregulating cortisol and norepinephrine in group $\mathrm{B}$ was lower than that in group $\mathrm{A}(\mathrm{P}<0.001)$. The total effective rate in group $B$ was higher than that in group $\mathrm{A}(\mathrm{P}<0.05)$. The perioperative related indexes, recovery,
\end{abstract}

Correspondence to: Dr Juan Yang, Department of General Surgery, Weifang People's Hospital, 151 Guangwen Street, Kuiwen, Weifang, Shandong 261041, P.R. China

E-mail: v262zs@163.com

Abbreviations: ELISA, enzyme-linked immunosorbent assay; TNF- $\alpha$, tumor necrosis factor- $\alpha$; CRP, C-reactive protein; IL-6, interleukin-6; IL- $\beta$, interleukin- $\beta$; NF- $\kappa \mathrm{B}$, nuclear factor $\kappa \mathrm{B}$

Key words: severe acute pancreatitis complicated with pancreatic pseudocyst, duodenoscopy, laparoscopy, IL-6, CRP, TNF- $\alpha$ and postoperative complications in group B were better than those in group $\mathrm{A}(\mathrm{P}<0.05)$. Scores of abdominal pain, nausea and vomiting in group B were markedly lower than those in group A $(\mathrm{P}<0.001)$. Multivariate Logistic regression analysis showed that CRP, TNF- $\alpha$, IL- 6 , IL- $\beta$ and surgical methods were independent risk factors for the prognosis of patients with SAP and PP. In conclusion, the combined treatment with duodenoscopy and laparoscopic surgery has little inflammatory and stress reaction, and it is highly safe, worthy to be popularized.

\section{Introduction}

Severe acute pancreatitis (SAP) is a common disease of the digestive system. It is characterized by acute onset and rapid course of disease $(1,2)$. Worldwide, the mortality of patients with SAP is as high as $20-30 \%$ every year $(3,4)$. Pancreatic pseudocyst (PP) is a common local complication of SAP which aggravates the condition of patients with SAP and seriously affects prognosis (5). If SAP complicated with PP is not treated in time, the aggravation of the disease will lead to pancreatic necrosis or multiple organ failure, causing renal failure, respiratory failure and shock, which greatly affect the health and life of patients (6). With the development of social economy and the bad living habits of people, the annual incidence of SAP complicated with PP is increasing year by year, with a younger trend (7). Moreover, the pathogenesis is relatively complex. Clinically, there is still a lack of accurate and better treatment standard (8).

In addition to conventional drug therapy, traditional laparotomy is currently the most commonly used treatment clinically for patients complicated with SAP and PP. However, traditional laparotomy causes great damage to tissues around the pancreas of patients, as well as inflammation and stress reaction of wounds, and the safety performance still needs to be improved $(9,10)$. With the rapid development of minimally invasive techniques, duodenoscopy and laparoscopy have been applied to pancreatitis surgery. It has been reported that, compared with traditional open surgery, duodenoscopy and laparoscopy can reduce the damage to tissues around pancreas and the risk of infection during surgery (11). At present, the clinical research on the application of holmium 
laser lithotripsy under electronic soft mirror to patients with renal calculi is limited. The present study assessed the clinical efficacy and value of a minimally invasive technique on patients complicated with SAP and PP by comparing the efficacy of traditional laparotomy with that of the combined treatment with duodenoscopy and laparoscopy, and investigating the related serum inflammatory, stress and prognosis factors.

\section{Patients and methods}

Patientcharacteristics.FromSeptember2015toDecember2018, 94 patients with SAP and PP were selected as the research subjects. Based on the different operation methods, 49 patients who underwent traditional laparotomy under laparoscopic surgery were included in group A (31 males and 18 females, with an average age of $45.30 \pm 3.79$ years) and 45 patients who underwent duodenoscopy and laparoscopic duodenoscopy for the nipple and pancreatic pseudocyst drainage treatment were included in group B (30 males and 15 females, with an average age of $44.94 \pm 3.89$ years). Inclusion criteria: Participants were all patients in Weifang People's Hospital (Weifang, China); the diagnostic criteria were in accordance with the diagnostic criteria for clinical SAP (12); patients were diagnosed with SAP complicated with PP by abdominal Doppler ultrasound, $\mathrm{CT}$ and other imaging examinations, and all of them presented secondary infection of acute PP before treatment; patients did not receive relevant antibacterial, anti-inflammatory or glucocorticoid treatment before surgery. Exclusion criteria: Patients complicated with severe liver and kidney dysfunction, coagulation disorders, or cognitive impairment and communication impairment; patients who had received treatment that could influence the operation methods before surgery, or those who did not cooperate with the examination. All subjects voluntarily participated in the study and provided a signed informed consent, and cooperated with the medical staff to complete the relevant diagnosis and treatment (medical research ethics approval no. WFRM1509PRC).

Surgical methods. Patients in group A received traditional laparotomy and surgical strategies, such as cystic jejunum Roux-en-Y, cystectomy and external drainage, whereas those in group B were treated with duodenoscopy when the main pancreatic duct was connected with the pancreatic cyst. Surgical drainage was conducted through nipple and PP. If ultrasonic endoscopy of patients showed that the cyst was not obviously compressing the stomach, cyst puncture stent implantation guided by the ultrasonic endoscope was adopted for treatment. If the ultrasonic results revealed an adhesion between the stomach wall and the capsule wall, the stomach tension was relatively high, then the treatment of electroacupuncture fenestration cyst drainage and stent implantation under gastroscope was adopted. If the implementation of duodenoscopy and laparoscopy was ineffective or failed, group A scheme was adopted for treatment. Preoperative evaluation and surgical indications of patients in groups A and B were evaluated in strict conformity with APACHE II scoring system. The preoperative condition evaluation and surgical indications of groups A and B were strictly in accordance with the clinical recommended APACHE II scoring system.
Determination of indicators. Venous blood was collected from the patients before surgery and at $48 \mathrm{~h}$ after surgery. The serum was separated and stored in a refrigerator at $80^{\circ} \mathrm{C}$ for testing. Enzyme-linked immunosorbent assay (ELISA) was used to determine tumor necrosis factor $\alpha$ (TNF- $\alpha)$, C-reactive protein (CRP), interleukin-6 (IL-6), interleukin- $\beta$ (IL- $\beta$ ), endotoxin and nuclear factor $\kappa \mathrm{B}(\mathrm{NF}-\kappa \mathrm{B})$ in serum.

The collected venous blood to be tested was put into a centrifuge, and the serum was separated at $1,500 \mathrm{xg}$ at $4^{\circ} \mathrm{C}$ for $10 \mathrm{~min}$. The concentrations of CRP, TNF- $\alpha$, IL- 6 , IL- $\beta$, endotoxin and NF- $\kappa \mathrm{B}$ in serum were tested by ELISA, with reference to human CRP (cat. no. ZK-H911), TNF- $\alpha$ (cat. no. ZK-R6070), IL-6 (cat. no. ZK-B7099), IL- $\beta$ (cat. no. ZK-B7085), endotoxin (cat. no. ZK-M5161) and NF-кB (cat. no. ZK-R4608). Each kit was taken out from the refrigerator $30 \mathrm{~min}$ in advance in order to balance the room temperature with that of the sample to be tested. The sample well, standard well and blank well were set up. A total of $50 \mu \mathrm{l}$ of sample diluent were added to the blank well, $100 \mu$ l of sample or standard substance to be tested were added to the other wells, the enzyme standard plate was covered with a film after being evenly mixed, and the wells were incubated for $2 \mathrm{~h}$ at $37^{\circ} \mathrm{C}$. The liquid was discarded from each well and spin-dried. Next, $100 \mu \mathrm{l}$ of working liquid A were added to each well, and they were filmed and incubated for $1 \mathrm{~h}$ at $37^{\circ} \mathrm{C}$. The liquid was discarded from each well and spin-dried, and the plate was washed 3 times with automatic plate washer. Next, $100 \mu \mathrm{l}$ of working solution B were added to each well, and they were filmed and incubated for $1 \mathrm{~h}$ at $37^{\circ} \mathrm{C}$. The liquid was discarded from each well, spin-dried and the plate was washed for 3 times. Afterwards, $90 \mu 1$ of substrate solution were added to each well, and they were filmed and developed for $20 \mathrm{~min}$ at room temperature under dark conditions. Finally, $50 \mu 1$ termination solution was added to each well, and the OD value was immediately detected at a wavelength of $450 \mathrm{~nm}$ using an enzyme-labeled analyzer. The concentrations of CRP, TNF- $\alpha$, IL- 6 , IL- $\beta$, endotoxin and $\mathrm{NF}-\kappa \mathrm{B}$ were determined.

Outcome measures. The changes of related serum indexes (CRP, TNF- $\alpha$, IL-6, IL- $\beta$, endotoxin and NF- $\kappa \mathrm{B}$ ) and serum stress indexes (cortisol and norepinephrine) before and at $48 \mathrm{~h}$ after surgery, the clinical efficacy (13), perioperative related indexes (duration of surgery, intraoperative blood loss, hospital stay, and recovery time of gastrointestinal function) and recovery conditions (exhaust time, time of body temperature recovery and relief time of abdominal pain) were compared between the two groups. The scores of postoperative nausea, vomiting and abdominal pain (14) were assessed. The complications (cyst infection, incision infection, pancreatic fistula, and gastrointestinal hemorrhage) 7 days after surgery were evaluated as well. The prognostic factors for patients were assessed via Logistic univariate and multivariate analyses. Clinical efficacy and postoperative prognosis were diagnosed by the clinical attending physician and relevant medical staff.

Determination of cortisol and norepinephrine. Cortisol and norepinephrine were determined by chemiluminescence. Cortisol chemiluminescence immunoassay kit was purchased from Shanghai Huzhen Industrial Co., Ltd. (cat. no. hz-0012c) and norepinephrine chemiluminescence immunoassay kit was 
Table I. General clinical data of patients in groups A and B [mean \pm SD, n (\%)].

\begin{tabular}{|c|c|c|c|c|}
\hline Characteristics & Group A $(n=49)$ & Group B $(n=45)$ & $t / \chi^{2}$ & P-value \\
\hline Age (years) & $45.30 \pm 3.79$ & $44.94 \pm 3.89$ & 0.454 & 0.651 \\
\hline Sex & & & 0.119 & 0.730 \\
\hline Male & $31(63.27)$ & $30(66.67)$ & & \\
\hline Female & $18(36.73)$ & $15(33.33)$ & & \\
\hline Course of disease (days) & $7.60 \pm 1.20$ & $7.80 \pm 1.40$ & & \\
\hline Size of cysts $(\mathrm{cm})$ & $4.10 \pm 1.20$ & $4.30 \pm 1.10$ & & \\
\hline Smoking & & & 0.327 & 0.568 \\
\hline Yes & $29(59.18)$ & $24(53.33)$ & & \\
\hline No & $20(40.82)$ & $21(46.67)$ & & \\
\hline Drinking & & & 0.010 & 0.921 \\
\hline Yes & $30(61.22)$ & $28(62.22)$ & & \\
\hline No & $19(38.78)$ & $17(37.78)$ & & \\
\hline Education background & & & 0.000 & 1.000 \\
\hline Bachelor's degree or above & $49(100.00)$ & $45(100.00)$ & & \\
\hline Below bachelor's degree & $0(0.00)$ & $0(0.00)$ & & \\
\hline Household registration & & & 0.000 & 0.979 \\
\hline Town & $23(46.94)$ & $21(46.67)$ & & \\
\hline Countryside & $26(53.06)$ & $24(53.33)$ & & \\
\hline Aetiological agent & & & 0.576 & 0.966 \\
\hline Biliary tract disease & $13(26.53)$ & $13(28.89)$ & & \\
\hline Overeating & $8(16.33)$ & $5(11.11)$ & & \\
\hline Pancreatic duct obstruction & $10(20.41)$ & $9(20.00)$ & & \\
\hline Endocrine and metabolic disorders & $8(16.33)$ & $8(17.78)$ & & \\
\hline Other & $10(20.41)$ & $10(22.22)$ & & \\
\hline
\end{tabular}

purchased from Shanghai Xinyu Biological Technology Co., Ltd. (cat. no. xy-CL-0030c).

Statistical analysis. SPSS 17.0 (Beijing Boyi Zhixun Information Technology Co., Ltd.) was used for statistical analysis. The counting data between the two groups were tested by $\chi^{2}$ test, and the risk factors related to the prognosis after surgery were assessed by single factor logistic regression analysis and multivariate logistic regression analysis. The normally distributed data were expressed as the mean \pm standard deviation (SD). The measurement data between groups were compared using independent samples t-test, and those of multiple time points were compared by repeated measures analysis of variance (ANOVA) and Bonferroni post hoc test. The comparison of mean values between groups was performed using one-way ANOVA and LSD-t test post hoc test. $\mathrm{P}<0.05$ was considered to indicate a statistically significant difference.

\section{Results}

General clinical data. There was no significant difference between the two groups in general clinical data $(\mathrm{P}>0.05)$. Details are presented in Table I.

Changes of serum inflammatory factors in groups $A$ and $B$ before and at $48 \mathrm{~h}$ after surgery. CRP in group A was
$27.53 \pm 3.28$ and $21.85 \pm 2.39 \mathrm{mg} / \mathrm{l}$ before surgery and $48 \mathrm{~h}$ after surgery, respectively; whereas CRP in group B was $28.10 \pm 3.02$ and $16.34 \pm 2.62 \mathrm{mg} / \mathrm{l}$ before surgery and $48 \mathrm{~h}$ after surgery, respectively. TNF- $\alpha$ in group A was $16.22 \pm 2.68$ and $8.39 \pm 2.56 \mathrm{pg} / \mathrm{ml}$ before surgery and $48 \mathrm{~h}$ after surgery, respectively; whereas TNF- $\alpha$ in group B was $17.01 \pm 2.14$ and $4.33 \pm 1.68 \mathrm{pg} / \mathrm{ml}$ before surgery and $48 \mathrm{~h}$ after surgery, respectively. IL-6 in group A was $43.26 \pm 2.15$ and $37.09 \pm 2.24 \mathrm{ng} / 1$ before surgery and $48 \mathrm{~h}$ after surgery, respectively; whereas IL-6 in group B was $43.29 \pm 2.04$ and $24.88 \pm 1.36 \mathrm{ng} / \mathrm{l}$ before surgery and $48 \mathrm{~h}$ after surgery, respectively. IL- $\beta$ in group A was $52.10 \pm 3.42$ and $39.08 \pm 2.09 \mathrm{ng} / \mathrm{l}$ before surgery and $48 \mathrm{~h}$ after surgery, respectively; whereas IL- $\beta$ in group B was $51.19 \pm 3.06$ and $27.63 \pm 1.27 \mathrm{ng} / \mathrm{l}$ before surgery and $48 \mathrm{~h}$ after surgery, respectively. Endotoxin levels in group A were $3.29 \pm 1.28$ and $2.59 \pm 0.69 \mathrm{pg} / \mathrm{ml}$ before surgery and $48 \mathrm{~h}$ after surgery, respectively; whereas those in group B were $3.26 \pm 1.29$ and $2.00 \pm 0.23 \mathrm{pg} / \mathrm{ml}$ before surgery and $48 \mathrm{~h}$ after surgery, respectively. NF- $\kappa \mathrm{B}$ in group A was $93.01 \pm 2.18$ and $87.51 \pm 2.04 \%$ before surgery and $48 \mathrm{~h}$ after surgery, respectively; whereas NF- $\mathrm{KB}$ in group B was $92.07 \pm 2.49$ and $81.06 \pm 1.09 \%$, respectively.

There was no marked difference in CRP, TNF- $\alpha$, IL-6, IL- $\beta$, endotoxin, and NF- $\mathrm{KB}$ between the two groups before surgery $(\mathrm{P}>0.05)$. However, the levels of CRP, TNF- $\alpha$, IL-6, IL- $\beta$, endotoxin and NF- $\kappa B$ in both groups after surgery were 
A
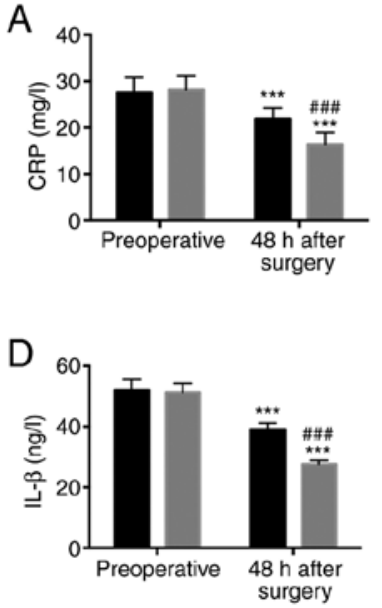

B
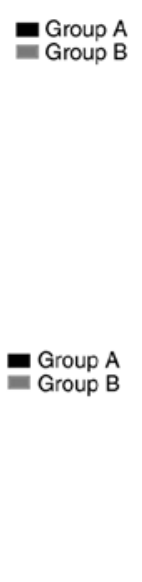
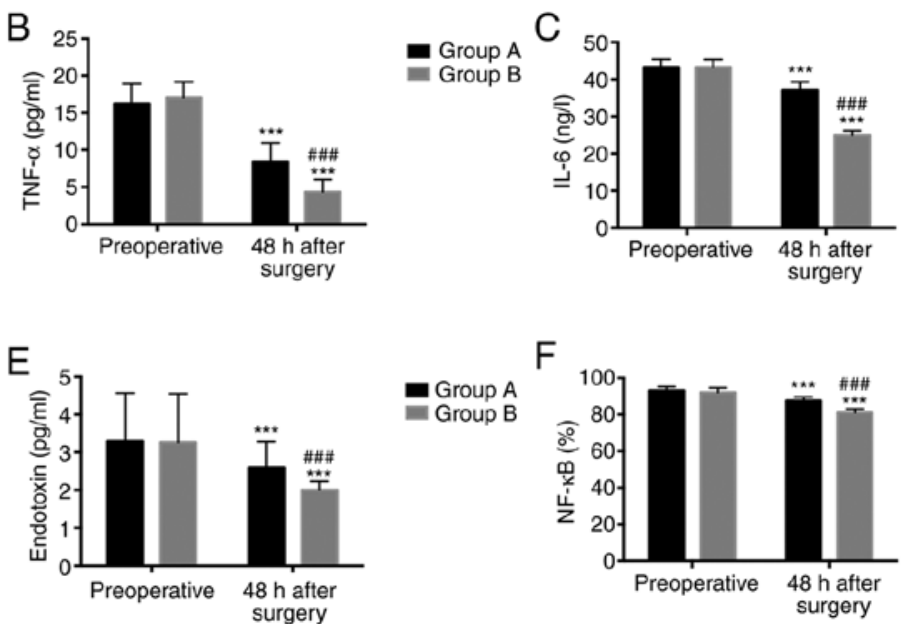

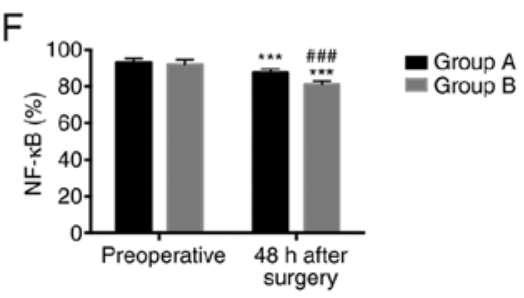

Figure 1. Changes of related serum indexes in groups $\mathrm{A}$ and $\mathrm{B}$, before and at $48 \mathrm{~h}$ after surgery. Compared with before treatment, the concentrations of (A) CRP, (B) TNF- $\alpha$, (C) IL-6, (D) IL- $\beta$, (E) endotoxin and (F) NF- $\kappa$ B after treatment were significantly lower in both groups. After treatment, the concentrations of the serum indexes in group B were significantly lower than those in group A, with statistically significant differences. ${ }^{* * *} \mathrm{P}<0.001$ and ${ }^{\# \# \#} \mathrm{P}<0.001$. $\mathrm{CRP}, \mathrm{C}$-reactive protein; TNF- $\alpha$, tumor necrosis factor- $\alpha$; IL-6, interleukin- 6 ; IL- $\beta$, interleukin- $\beta$; NF- $\kappa$ B, nuclear factor $\kappa$ B.
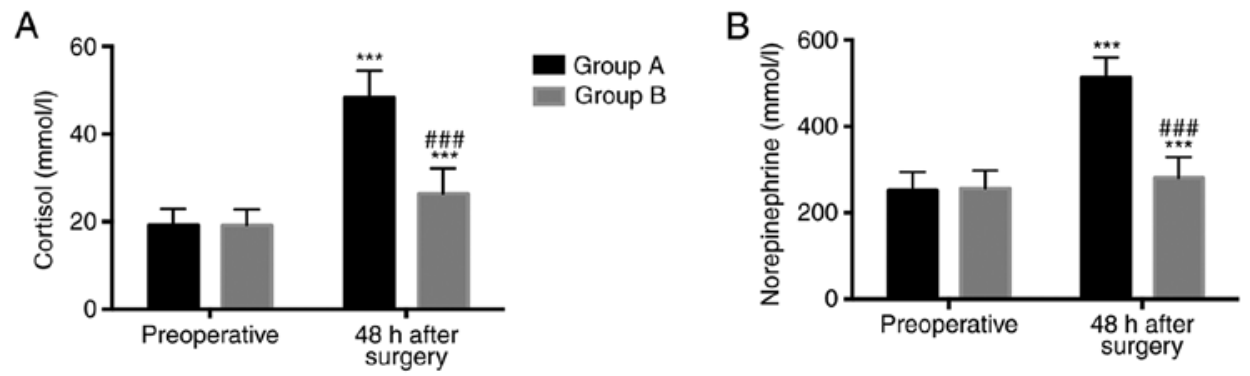

Figure 2. Changes of related serum stress indexes in groups A and B, before and at $48 \mathrm{~h}$ after surgery. Compared with before treatment, the concentrations of (A) cortisol and (B) norepinephrine after treatment were significantly higher in both groups, and the concentrations after treatment in group B were significantly lower than those in group $\mathrm{A}$, with statistically significant differences. ${ }^{* * *} \mathrm{P}<0.001$ and ${ }^{\# \#} \mathrm{P}<0.001$.

significantly lower than those before surgery, and the levels in group $B$ after surgery were significantly lower than those in group $\mathrm{A}(\mathrm{P}<0.001)$ (Fig. 1).

Changes of serum stress indexes before and 48 h after surgery

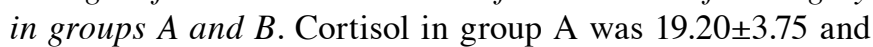
$48.20 \pm 6.29 \mathrm{mmol} / \mathrm{l}$ before surgery and $48 \mathrm{~h}$ after surgery, respectively; whereas, cortisol in group B was $19.18 \pm 3.63$ and $26.37 \pm 5.82 \mathrm{mmol} / \mathrm{l}$ before surgery and $48 \mathrm{~h}$ after surgery, respectively. Norepinephrine in group A was $251.47 \pm 42.92$ and $513.20 \pm 45.94 \mathrm{mmol} / 1$ before surgery and $48 \mathrm{~h}$ after surgery, respectively; whereas norepinephrine in group B was $256.10 \pm 41.71$ and $281.44 \pm 47.29 \mathrm{mmol} / 1$ before surgery and $48 \mathrm{~h}$ after surgery, respectively.

There was no marked difference in cortisol and norepinephrine between the two groups before surgery $(\mathrm{P}>0.05)$. However, the levels of cortisol and norepinephrine in both groups after surgery were significantly higher than those before surgery, and the upregulation of the two in group $B$ after surgery was lower than that in group $\mathrm{A}(\mathrm{P}<0.001)$ (Fig. 2).

Clinical efficacy in groups $A$ and $B$. In group $A$, there were 10 cases of patients with markedly effective treatment response, 24 with effective treatment response, 15 with ineffective treatment response, and the total effective rate was $69.39 \%$. In group B, there were 21 cases of patients with markedly effective response, 21 with effective treatment response, 3 with ineffective treatment response, and the total effective rate was $93.33 \%$. The total effective rate in group $\mathrm{B}$ was higher than that of group $\mathrm{A}(\mathrm{P}<0.05)$ (Table II).

Perioperative related indexes in groups $A$ and $B$. The total duration of surgery in group A was $148.02 \pm 28.39 \mathrm{~min}$, the amount of bleeding during surgery was $350.89 \pm 34.90 \mathrm{ml}$, the hospital stays was $15.20 \pm 5.29$ days and the recovery time of gastrointestinal function was $36.02 \pm 6.92 \mathrm{~h}$. The total duration of surgery in group B was $102.29 \pm 26.04 \mathrm{~min}$, the intraoperative blood loss was $163.29 \pm 31.28 \mathrm{ml}$, the hospital stays was $8.43 \pm 3.05$ days and the recovery time of gastrointestinal function was $26.02 \pm 7.16 \mathrm{~h}$. The perioperative related indexes in group B were better than those in group A. Differences in total duration of surgery, intraoperative blood loss, hospital stay and recovery time of gastrointestinal function between the two groups were statistically remarkable $(\mathrm{P}<0.001)$ (Table III).

Recovery of patients in the two groups.

Improvement of clinical symptoms of patients in groups $A$ and $B$. The exhaust time of patients in group A was 
Table II. Clinical efficacy in groups A and B [n (\%)].

\begin{tabular}{|c|c|c|c|c|}
\hline Efficacy & Group A $(n=49)$ & Group B $(n=45)$ & $\chi^{2}$ & P-value \\
\hline Markedly effective & $10(20.41)$ & $21(46.67)$ & - & - \\
\hline Effective & $24(48.98)$ & $21(46.67)$ & - & - \\
\hline Ineffective & $15(30.61)$ & $3(6.67)$ & - & - \\
\hline Total efficacy & 34 (69.39) & $42(93.33)$ & 8.688 & 0.003 \\
\hline
\end{tabular}

Table III. Perioperative related indicators in groups A and B (mean $\pm \mathrm{SD})$.

\begin{tabular}{lcrr}
\hline Indicators & Group A (n=49) & Group B (n=45) & $\mathrm{t}$ \\
\hline Duration of surgery (min) & $148.02 \pm 28.39$ & $102.29 \pm 26.04$ & 8.116 \\
Intraoperative blood loss (ml) & $350.89 \pm 34.90$ & $163.29 \pm 31.28$ & 27.350 \\
Hospital stay (days) & $15.20 \pm 5.29$ & $8.43 \pm 3.05$ & $<0.001$ \\
Recovery time of gastrointestinal function (h) & $36.02 \pm 6.92$ & $26.02 \pm 7.16$ & $<13$ \\
\hline
\end{tabular}

Table IV. Improvement of clinical symptoms and signs in patients of groups A and B (mean \pm SD).

\begin{tabular}{lrrr}
\hline Variables & Group A (n=49) & Group B (n=45) & $\mathrm{t}$ \\
\hline Anal exhaust time (days) & $14.01 \pm 2.31$ & $12.62 \pm 2.49$ & 0.006 \\
Body temperature recovery time (days) & $8.20 \pm 1.23$ & $4.16 \pm 1.52$ & 2.808 \\
Abdominal pain relief time (h) & $5.29 \pm 0.93$ & $2.82 \pm 0.58$ & 14.22 \\
\hline
\end{tabular}
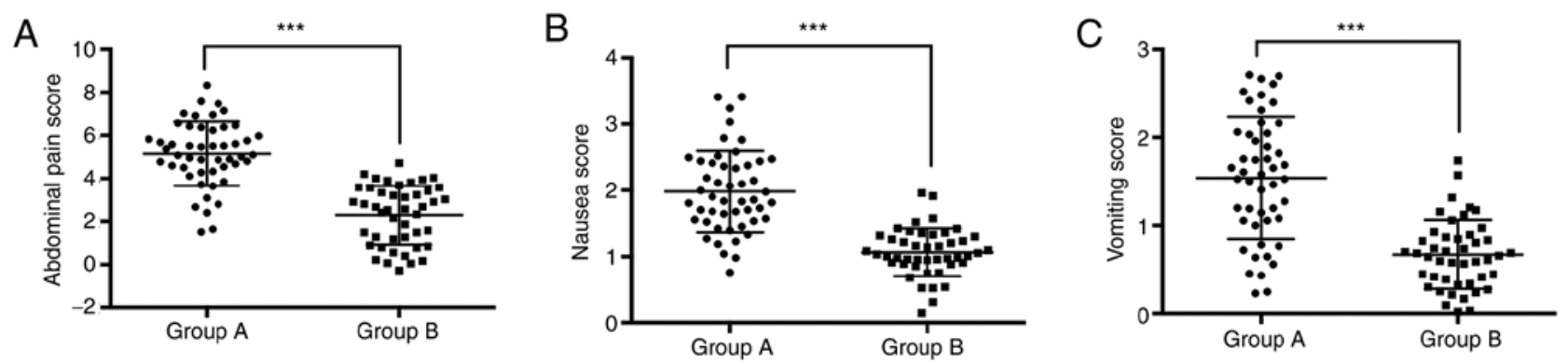

Figure 3. Score analysis of postoperative nausea, vomiting and abdominal pain in groups A and B. Compared with before treatment, (A) the abdominal pain score, $(\mathrm{B})$ the nausea score and $(\mathrm{C})$ the vomiting score in group B after treatment were significantly lower than those in group A, with statistically significant differences. ${ }^{* * *} \mathrm{P}<0.001$.

$14.01 \pm 2.31$ days, the recovery time of body temperature was $8.20 \pm 1.23$ days and the relief time of abdominal pain was $5.29 \pm 0.93 \mathrm{~h}$. The exhaust time of patients in group B was $12.62 \pm 2.49$ days, the recovery time of body temperature was $4.16 \pm 1.52$ days and the relief time of abdominal pain was $2.82 \pm 0.58 \mathrm{~h}$. Differences in exhaust time, body temperature recovery time and abdominal pain relief time between the two groups were markedly significant $(\mathrm{P}<0.05)$. Compared with the patients in group A, those in group B presented greater improvement as expressed by clinical symptoms (Table IV).

Score analysis of postoperative nausea, vomiting, and abdominal pain in patients of groups $A$ and $B$. The postoperative abdominal pain score in group A was 5.10 \pm 1.49 , nausea score was $1.98 \pm 0.58$ and vomiting score was $1.55 \pm 0.78$. The postoperative abdominal pain score in group B was $2.32 \pm 1.10$, nausea score was $0.94 \pm 0.43$ and vomiting score was $0.62 \pm 0.46$. The postoperative abdominal pain score, nausea score and vomiting score of patients in group B were significantly lower than those in group A $(\mathrm{P}<0.05)$ (Fig. 3).

Analysis of complications of patients in groups $A$ and $B$ at 7 days after surgery. The total complication rate due to cyst infection, incision infection, pancreatic fistula and gastrointestinal hemorrhage was lower in group B than that in group A; however, the differences were not statistically significant (P>0.05) (Table V). 
Table V. Analysis of complications in groups A and B at 7 days after surgery [n (\%)].

\begin{tabular}{lcccc}
\hline Complications & Group A (n=49) & Group B (n=45) & $\chi^{2}$ & P-value \\
\hline Cyst infection & $2(4.08)$ & $1(2.22)$ & - & - \\
Incision infection & $2(4.08)$ & $1(2.22)$ & - & - \\
Pancreatic fistula & $2(4.08)$ & $0(0.00)$ & - & - \\
Gastrointestinal hemorrhage & $3(6.12)$ & $1(2.22)$ & - & - \\
Total complications & $9(18.37)$ & $3(6.67)$ & 2.884 & 0.090 \\
\hline
\end{tabular}

Table VI. Univariate analysis of related factors for prognosis of patients [mean $\pm \mathrm{SD}, \mathrm{n}(\%)]$.

\begin{tabular}{|c|c|c|c|c|}
\hline Factors & $\begin{array}{l}\text { Good prognosis } \\
\text { group }(n=60)\end{array}$ & $\begin{array}{l}\text { Poor prognosis } \\
\text { group }(n=34)\end{array}$ & $\mathrm{t} / \chi^{2}$ & P-value \\
\hline Age (years) & $45.40 \pm 3.60$ & $44.60 \pm 3.40$ & 1.056 & 0.294 \\
\hline Sex & & & 1.223 & 0.346 \\
\hline Male & $38(63.33)$ & $24(70.59)$ & & \\
\hline Female & $22(36.67)$ & $10(29.41)$ & & \\
\hline Aetiological agent & & & 0.370 & 0.985 \\
\hline Biliary tract disease & $17(28.33)$ & $9(26.47)$ & & \\
\hline Overeating & $8(13.33)$ & $5(14.71)$ & & \\
\hline Pancreatic duct obstruction & $13(21.67)$ & $6(17.65)$ & & \\
\hline Endocrine and metabolic disorders & $10(16.67)$ & $6(17.65)$ & & \\
\hline Other & $12(20.00)$ & $8(23.53)$ & & \\
\hline $\mathrm{CRP}(\mathrm{mg} / \mathrm{l})$ & $15.29 \pm 2.01$ & $20.73 \pm 2.17$ & 12.250 & $<0.001$ \\
\hline TNF- $\alpha(\mathrm{pg} / \mathrm{ml})$ & $4.29 \pm 1.22$ & $9.13 \pm 2.74$ & 11.810 & $<0.001$ \\
\hline IL-6 (ng/l) & $25.10 \pm 1.32$ & $38.29 \pm 2.54$ & 33.170 & $<0.001$ \\
\hline $\mathrm{IL}-\beta(\mathrm{ng} / \mathrm{l})$ & $25.19 \pm 1.31$ & $39.05 \pm 2.77$ & 33.110 & $<0.001$ \\
\hline Endotoxin $(\mathrm{pg} / \mathrm{ml})$ & $1.97 \pm 0.28$ & $2.62 \pm 0.71$ & 6.299 & $<0.001$ \\
\hline $\mathrm{NF}-\mathrm{kB}(\%)$ & $78.23 \pm 1.04$ & $88.20 \pm 2.52$ & 26.94 & $<0.001$ \\
\hline Surgical methods & & & 48.920 & $<0.001$ \\
\hline Duodenoscopy combined with laparoscopy & $45(75.00)$ & $0(0.00)$ & & \\
\hline Open surgery & $15(25.00)$ & $34(100.00)$ & & \\
\hline Abdominal pain score & $2.01 \pm 1.05$ & $4.78 \pm 1.13$ & 11.960 & $<0.001$ \\
\hline Nausea score & $0.82 \pm 0.26$ & $1.73 \pm 0.42$ & 12.980 & $<0.001$ \\
\hline Vomiting score & $0.58 \pm 0.27$ & $1.53 \pm 0.72$ & 9.174 & $<0.001$ \\
\hline
\end{tabular}

CRP, C-reactive protein; TNF- $\alpha$, tumor necrosis factor- $\alpha$; IL-6, interleukin- 6 ; IL- $\beta$, interleukin- $\beta$; NF- $\kappa \mathrm{B}$, nuclear factor $\kappa \mathrm{B}$.

Analysis of prognostic factors of patients in groups $A$ and $B$. According to the prognosis of patients after 30 days, the patients were divided into two groups under the evaluation of the relevant attending doctors. Sixty patients with good prognosis were included in the good prognosis group and 34 with poor prognosis were included in the poor prognosis group. The prognostic factors related to SAP complicated with $\mathrm{PP}$ were assessed via Logistic univariate and multivariate analyses.

i) Univariate analysis of prognostic factors in patients with $S A P$ and PP. Logistic univariate analysis of factors related to prognosis of patients with SAP and PP showed that CRP,
TNF- $\alpha$, IL-6, IL- $\beta$, endotoxin, NF- $\kappa$ B, surgical methods, abdominal pain scores, vomiting scores and nausea scores had significant differences between the two groups $(\mathrm{P}<0.05)$. These factors were all related to the prognosis of patients with SAP and PP and were the risk factors for poor prognosis, as shown in Table VI.

ii) Multivariate analysis of prognostic factors in patients with SAP and PP. Risk factors related to the prognosis of patients were analyzed by multivariate conditional Logistic regression analysis. The results revealed that CRP, TNF- $\alpha$, IL-6, IL- $\beta$ and the surgical methods were independent risk factors for the prognosis of patients with SAP and PP, as shown in Table VII. 
Table VII. Multivariate analysis of related factors for prognosis of patients complicated with SAP and PP.

\begin{tabular}{|c|c|c|c|c|c|c|}
\hline Factors & $\beta$ & SE & Wald & P-value & $\operatorname{Exp}(\beta)$ & $95 \% \mathrm{CI}$ \\
\hline CRP & 2.170 & 1.065 & 4.003 & 0.039 & 8.206 & $0.392-48.397$ \\
\hline TNF- $\alpha$ & 0.047 & 0.082 & 3.892 & 0.047 & 3.109 & $1.392-42.118$ \\
\hline IL-6 & 2.368 & 1.692 & 5.090 & 0.021 & 9.145 & $0.089-39.950$ \\
\hline IL- $\beta$ & 3.162 & 0.465 & 10.477 & 0.012 & 9.704 & $0.445-17.204$ \\
\hline Endotoxin & 3.006 & 2.089 & 8.028 & 0.398 & 6.154 & $1.778-23.326$ \\
\hline $\mathrm{NF}-\kappa \mathrm{B}$ & 3.129 & 2.765 & 8.753 & 0.440 & 7.093 & $1.924-21.372$ \\
\hline Surgical methods & 0.069 & 0.032 & 4.320 & 0.040 & 5.184 & $1.029-23.845$ \\
\hline Abdominal pain score & 1.093 & 1.114 & 4.082 & 0.239 & 4.112 & $0.054-29.357$ \\
\hline Nausea score & 1.823 & 1.659 & 4.376 & 0.301 & 4.276 & $1.104-20.659$ \\
\hline Vomiting score & 2.524 & 1.740 & 4.875 & 0.377 & 8.720 & $1.223-19.219$ \\
\hline
\end{tabular}

SAP, severe acute pancreatitis; PP, pancreatic pseudocyst; CRP, C-reactive protein; TNF- $\alpha$, tumor necrosis factor- $\alpha$; IL-6, interleukin-6; IL- $\beta$, interleukin- $\beta$; NF- $\kappa \mathrm{B}$, nuclear factor $\kappa \mathrm{B} ; \mathrm{CI}$, confidence interval.

\section{Discussion}

PP is a pancreatic cyst lined by pancreatic epithelial cells gradually caused by adhesion of adjacent tissues around the pancreas in patients with acute or chronic pancreatitis (15). According to a previous study, if PP is not absorbed naturally or treated correctly, other complications, such as swollen bursa rupture and intracapsular hemorrhage, will occur which will aggravate the disease (16). At present, the continuous development of minimally invasive surgical techniques in clinical practice has diversified the surgical schemes for SAP complicated with PP (17).

Duodenoscopy combined with laparoscopic surgery is a combined method during which a support frame is implanted between the cyst and the stomach of the patient under the guidance of endoscopy so that the cyst can enter the stomach more smoothly, making its removal much more convenient, and greatly reducing the pain after surgery (18). This method plays an important role in the clinical treatment of SAP complicated with PP (19). In the present study, the clinical efficacy of duodenoscopy combined with laparoscopic surgery was higher than that of laparotomy alone. The perioperative indexes, such as total duration of surgery, intraoperative blood loss, hospital stay and recovery time of gastrointestinal function, were significantly better in patients receiving the combined treatment than those undergoing traditional laparotomy. The complications due to cyst infection, incision infection, pancreatic fistula and gastrointestinal hemorrhage were also less after the combined treatment. Moreover, postoperative nausea, vomiting, and abdominal pain scores in patients treated with the combination of duodenoscopy and laparoscopy were significantly lower than those of patients treated with traditional laparotomy. Therefore, we believe that the combination of duodenoscopy and laparoscopy is more reliable in ensuring the safety and clinical efficacy of SAP and PP treatment.

A recent study has reported that the prognosis of patients with SAP and PP is relevant to local or systemic stress reactions and inflammatory reactions induced during surgery. Further expression of a large number of cytokines can also cause pathological damage (20). TNF- $\alpha$ in serum is a vital regulatory factor in the process of inflammatory reaction. TNF- $\alpha$ initiates the inflammatory effect in resection surgery and together with other inflammatory cytokines initiates and maintains inflammatory reaction (21). CRP is a sensitive indicator reflecting whether the body is infected or not. CRP has been reported to increase significantly when infection occurs after resection (22). A study has also shown that TNF- $\alpha$ is the initial factor of inflammatory response in SAP complicated with PP. Further expression of TNF- $\alpha$ can induce high expressions of IL- 6 , IL- $\beta$ and other cytokines, causing further damage to tissue and organs at the inflammatory site (23). Surgery activates the body's stress response. When the body is subjected to noxious stimulation, such as surgery, anesthesia and trauma, a series of neuroendocrine activities that cause metabolic changes appear in the body. Moreover, the more severe the surgical trauma is, the more intense the stress response of the body is, and the concentration of cortisol and norepinephrine in pituitary-adrenal cortex in circulating blood also increases suddenly (24). According to the results of the present study, there was no marked difference between the two groups in serum indexes and serum stress indexes before surgery. However, the levels of CRP, TNF- $\alpha$, IL-6, IL- $\beta$, endotoxin and $\mathrm{NF}-\kappa \mathrm{B}$ in the two groups after surgery were significantly lower than those before surgery. The levels of cortisol and norepinephrine in both groups after surgery were significantly higher than those before surgery. CRP, TNF- $\alpha$, IL-6, IL- $\beta$, endotoxin and NF- $\kappa$ B in group B after surgery were significantly lower than those in group A. As a result, the treatment plan of duodenoscopy combined with laparoscopic surgery for patients with SAP and PP has little effect on the inflammatory response and stress response of the body, which is conducive to the fast recovery of patients after surgery. Finally, according to the prognosis assessment of patients after 30 days, the relevant prognostic factors were investigated. It was shown that CRP, TNF- $\alpha$, IL- 6 , IL- $\beta$, endotoxin, NF- $\kappa$ B, surgical methods, abdominal pain score, vomiting score and nausea score were all related to the prognosis of patients with SAP and PP, and were the risk factors for poor prognosis. CRP, TNF- $\alpha$, IL- 6 , IL- $\beta$ and surgical methods were independent risk factors for the prognosis of patients with SAP and 
PP. Some studies have also reported that different surgical methods directly affect the prognosis of patients (25-27). A recent study has confirmed that the prognosis of patients with SAP also needs long-term monitoring of serum inflammatory factors (28).

The present study focused on the clinical efficacy of duodenoscopy combined with laparoscopy in the treatment of patients with SAP and PP. The results revealed that the safety of duodenoscopy combined with laparoscopy was high, and the influence on IL-6 and CRP was less volatile. However, there are still some limitations. For example, the relationship of different IL-6 and CRP fluctuations with the prognosis of patients, as well as the relationship between other routine biochemical indicators and the progress of surgery need to be further analyzed.

In conclusion, implementing duodenoscopy combined with laparoscopic surgery for SAP complicated with PP induces small inflammatory and stress response, and it is highly safe, worthy to be popularized.

\section{Acknowledgements}

Not applicable.

\section{Funding}

No funding was received.

\section{Availability of data and materials}

The datasets used and/or analyzed during the present study are available from the corresponding author on reasonable request.

\section{Authors' contributions}

LZ designed the study. SH performed the experiments. FL and SH measured outcomes and determined cortisol and norepinephrine. JY analyzed the data. SH wrote the manuscript. All authors read and approved the final manuscript.

\section{Ethics approval and consent to participate}

The study was approved by the Ethics Committee of Weifang People's Hospital (Weifang, China) (ethics approval no. WFRM1509PRC). Patients who participated in the study had complete clinical data. Signed written informed consents were obtained from the patients and/or guardians.

\section{Patient consent for publication}

Not applicable.

\section{Competing interests}

The authors declare that they have no competing interests.

\section{References}

1. De Waele E, Malbrain MLNG and Spapen HD: How to deal with severe acute pancreatitis in the critically ill. Curr Opin Crit Care 25: 150-156, 2019
2. Hong W, Lillemoe KD, Pan S, Zimmer V, Kontopantelis E, Stock S, Zippi M, Wang C and Zhou M: Development and validation of a risk prediction score for severe acute pancreatitis. J Transl Med 17: 146, 2019.

3. Lucas FRC, Carvalho AF and Louro F: Critical shock-related acute pancreatitis. EC Gastroenterol Dig Syst 6: 19-22, 2019.

4. Jabaudon M, Belhadj-Tahar N, Rimmelé T, Joannes-Boyau O, Bulyez S, Lefrant JY, Malledant Y, Leone M, Abback PS, Tamion F, et al: Thoracic epidural analgesia and mortality in acute pancreatitis: A multicenter propensity analysis. Crit Care Med 46: e198-e205, 2018.

5. Italian Association for the Study of the Pancreas (AISP), PezzilliR, Zerbi A, Campra D, Capurso G, Golfieri R, Arcidiacono PG, Billi P, Butturini G, Calculli L, et al: Consensus guidelines on severe acute pancreatitis. Dig Liver Dis 47: 532-543, 2015.

6. Manrai M, Kochhar R, Gupta V, Yadav TD, Dhaka N, Kalra N, Sinha SK and Khandelwal N: Outcome of acute pancreatic and peripancreatic collections occurring in patients with acute pancreatitis. Ann Surg 267: 357-363, 2018.

7. Doane SM and Yeo CJ: Pseudocysts and other complications of pancreatitis. Shackelford's surgery of the alimentary tract, 2. 8th edition, pp1097-1112, 2019.

8. Augustin G: Surgical emergencies during pregnancy. In: Acute Care Surgery Handbook. Di Saverio S, Catena F, Ansaloni L, Coccolini F and Velmahos G (eds). Vol 2. Spring Cham, pp485-507, 2017.

9. Alaa A, Mostafa R, Hamad A and Omar M: Pancreatic pseudocyst dilemma; cumulative multi-centers experience in management using endoscopy, laparoscopy, and open surgery. HPB 20 (Suppl 1): S119-SS172, 2018.

10. Matsuoka L and Alexopoulos SP: Surgical management of pancreatic pseudocysts. Gastrointest Endosc Clin N Am 28: 131-141, 2018.

11. Saleem A, Sawyer MD and Baron TH: Laparoscopy assisted transjejunal ERCP for treatment of pancreaticopleural fistula. JOP 11: 69-71, 2010.

12. Sugimoto M, Sonntag DP, Flint GS, Boyce CJ, Kirkham JC, Harris TJ, Carr SM, Nelson BD, Bell DA, Barton JG and Traverso LW: Biliary stenosis and gastric outlet obstruction: Late complications after acute pancreatitis with pancreatic duct disruption. Pancreas 47: 772-777, 2018.

13. Dimcevski G, Kotopoulis S, Bjånes T, Hoem D, Schjøtt J, Gjertsen BT, Biermann M, Molven A, Sorbye $H$, McCormack E, et al: A human clinical trial using ultrasound and microbubbles to enhance gemcitabine treatment of inoperable pancreatic cancer. J Control Release 243: 172-181, 2016.

14. Barai B, Mandal A, Chakraborty P, Bhattacharyya S and Bala S: Spectrum of diseases in patients with non-traumatic acute abdominal pain presenting to general surgery department in a rural tertiary care centre in West Bengal. Int J Sci Res 5: 1244-1248, 2016.

15. Sharaiha RZ, DeFilippis EM, Kedia P, Gaidhane M, Boumitri C, Lim HW, Han E, Singh H, Ghumman SS, Kowalski T, et al: Metal versus plastic for pancreatic pseudocyst drainage: clinical outcomes and success. Gastrointest Endoc 82: 822-827, 2015.

16. Zerem E, Hauser G, Loga-Zec S, Kunosić S, Jovanović P and Crnkić D: Minimally invasive treatment of pancreatic pseudocysts. World J Gastroenterol 21: 6850-6860, 2015.

17. Senthilnathan P, Gurumurthy SS and Palanivelu C: Minimally invasive pancreatic surgery: What the future holds for this field? GI Surgery Annual. In: Chattopadhyay T, Sahni P and Pal S (eds). GI Surgery Annual, volume 24. Spring Singapore, pp131-152, 2018. http://doi-org-443.webvpn.fjmu.edu.cn/10.1007/978-98113-0161-2_6.

18. Teoh AY, Dhir V, Jin ZD, Kida M, Seo DW and Ho KY: Systematic review comparing endoscopic, percutaneous and surgical pancreatic pseudocyst drainage. World J Gastrointest Endosc 8: 310-318, 2016.

19. Shekhar C, Maher B, Forde C and Mahon BS: Endoscopic ultrasound-guided pancreatic fluid collections' transmural drainage outcomes in 100 consecutive cases of pseudocysts and walled off necrosis: A single-centre experience from the United Kingdom. Scand J Gastroenterol 53: 611-615, 2018.

20. Chen YJ, Zhuang YD, Cai Z, Zhang YN and Guo SR: Effects of enteral nutrition on pro-inflammatory factors and intestinal barrier function in patients with acute severe pancreatitis. Eur J Inflamm 17: 2058739219827212, 2019. 
21. DelaCruz-Mosso U,García-Iglesias T,BucalaR,Estrada-GarcíaI, González-López L, Cerpa-Cruz S, Parra-Rojas I, Gámez-Nava JI, Pérez-Guerrero EE and Muñoz-Valle JF: MIF promotes a differential Th1/Th2/Th17 inflammatory response in human primary cell cultures: Predominance of Th17 cytokine profile in PBMC from healthy subjects and increase of IL- 6 and TNF- $\alpha$ in PBMC from active SLE patients. Cell Immunol 324: 42-49, 2018.

22. Chohno T, Uchino M, Sasaki H, Bando T, Takesue $Y$ and Ikeuchi H: Associations between the prognostic nutritional index and morbidity/mortality during intestinal resection in patients with ulcerative colitis. World J Surg 42: 1949-1959, 2018.

23. Wang YS, Li YY, Wang LH, Kang Y, Zhang J, Liu ZQ, Wang K, Kaye AD and Chen L: Tanshinone IIA attenuates chronic pancreatitis-induced pain in rats via downregulation of HMGB1 and TRL4 expression in the spinal cord. Pain Physician 18: E615-E628, 2015.

24. Abd-Elshafy SK, Khalaf GS, Abo-Kerisha MZ, Ahmed NT, Abd El-Aziz MA and Mohamed MA: Not all sounds have negative effects on children undergoing cardiac surgery. J Cardiothorac Vasc Anesth 29: 1277-1284, 2015.
25. Mingrone G, Panunzi S, De Gaetano A, Guidone C, Iaconelli A, Nanni G, Castagneto M, Bornstein S and Rubino F: Bariatric-metabolic surgery versus conventional medical treatment in obese patients with type 2 diabetes: 5 year follow-up of an open-label, single-centre, randomised controlled trial. Lancet 386: 964-973, 2015.

26. Sliwińska-Mossoń M, Milnerowicz H, Jabłonowska M, Milnerowicz S, Nabzdyk S and Rabczyński J: The effect of smoking on expression of IL-6 and antioxidants in pancreatic fluids and tissues in patients with chronic pancreatitis. Pancreatology 12: 295-304, 2012.

27. Weng SC, Jiang CB, Chi H, Shih SL, Chan U and Lee HC: A 7-year-old girl with early developed pseudocyst after acute pancreatitis: A case report and literature review. J Med Ultrasound 25: 109-114, 2017.

28. Jin Z, Xu L, Wang X and Yang D: Risk factors for worsening of acute pancreatitis in patients admitted with mild acute pancreatitis. Med Sci Monit 23: 1026-1032, 2017. 